\title{
Honey Bee Thermal/Chemical Sensor, AmHsTRPA, Reveals Neofunctionalization and Loss of Transient Receptor Potential Channel Genes
}

\author{
Keigo Kohno, ${ }^{1 *}$ Takaaki Sokabe, ${ }^{2 \star}$ Makoto Tominaga, ${ }^{2,3}$ and Tatsuhiko Kadowaki ${ }^{1}$ \\ ${ }^{1}$ Graduate School of Bioagricultural Sciences, Nagoya University, Chikusa, Nagoya 464-8601, Japan, ${ }^{2}$ Division of Cell Signaling, Okazaki Institute for \\ Integrative Bioscience (National Institute for Physiological Sciences), National Institutes of Natural Sciences, Okazaki 444-8787, Japan, and ${ }^{3}$ Department of \\ Physiological Sciences, The Graduate University for Advanced Studies, Okazaki 444-8585, Japan
}

Insects are relatively small heterothermic animals, thus they are highly susceptible to changes in ambient temperature. However, a group of honey bees is able to maintain the brood nest temperature between $32^{\circ} \mathrm{C}$ and $36^{\circ} \mathrm{C}$ by either cooling or heating the nest. Nevertheless, how honey bees sense the ambient temperature is not known. We identified a honey bee Hymenoptera-specific transient receptor potential A (HsTRPA) channel (AmHsTRPA), which is activated by heat with an apparent threshold temperature of $34^{\circ} \mathrm{C}$ and insect antifeedants such as camphor in vitro. AmHsTRPA is expressed in the antennal flagellum, and ablation of the antennal flagella and injection of AmHsTRPA inhibitors impair warmth avoidance of honey bees. Gustatory responses of honey bees to sucrose are suppressed by noxious heat and insect antifeedants, but are relieved in the presence of AmHsTRPA inhibitors. These results suggest that AmHsTRPA may function as a thermal/chemical sensor in vivo. As shown previously, Hymenoptera has lost the ancient chemical sensor TRPA1; however, AmHsTRPA is able to complement the function of Drosophila melanogaster TRPA1. These results demonstrate that HsTRPA, originally arisen by the duplication of Water witch, has acquired thermal- and chemical-responsive properties, which has resulted in the loss of ancient TRPA1. Thus, this is an example of neofunctionalization of the duplicated ion channel gene followed by the loss of the functionally equivalent ancient gene.

\section{Introduction}

Insects have been very successful in adapting their habitats to various environments. Nevertheless, they are highly susceptible to changes in ambient temperature and humidity because they are heterothermic and have a larger ratio of surface area to volume than mammals because of their relatively small sizes. This may suggest that evolutionary processes of both thermosensation and hygrosensation are different between insects and mammals. These sensory modalities are known to depend on transient receptor potential (TRP) channels in Drosophila melanogaster (Tracey et al., 2003; Lee et al., 2005; Liu et al., 2007; Hamada et al., 2008; Kwon et al., 2008). Drosophila TRPA1 (DmTRPA1) (Hamada et al., 2008; Kwon et al., 2008), Painless (Pain) (Tracey et al., 2003; Sokabe et al., 2008), and Pyrexia (Pyx) (Lee et al., 2005) respond to heat stimulation in vitro and are essential for various temperature-related behaviors. Nanchung (Nan) and Water witch (Wtrw) are essential for detecting dry and moist air,

\footnotetext{
Received April 17, 2010; revised June 23, 2010; accepted July 20, 2010.

This study was supported by Grant-in-Aid for Scientific Research (T.K.). We thank Y. Hasada, C. Montell, and P. Garrity for providing honey bees and fly stocks for the experiments.

*K.K. and T.S. contributed equally to this work.

Correspondence should be addressed to Tatsuhiko Kadowaki, Graduate School of Bioagricultural Sciences, Nagoya University, Chikusa, Nagoya 464-8601, Japan. E-mail: emi@nuagr1.agr.nagoya-u.ac.jp.

T. Sokabe's present address: Department of Biological Chemistry and Neuroscience, Center for Sensory Biology,

The Johns Hopkins University School of Medicine, Baltimore, MD 21205. E-mail: tsokabe1@jhmi.edu.

DOI:10.1523/JNEUROSCI.2001-10.2010

Copyright $\odot 2010$ the authors $\quad 0270-6474 / 10 / 3012219-11 \$ 15.00 / 0$
}

respectively in Drosophila (Liu et al., 2007). All of the above TRP channels are TRPA subfamily members except Nan, which is one of two Drosophila TRPV channels. Thus, in Drosophila, three of the four TRPA channels are involved in thermosensation.

Honey bees (Apis mellifera) share the same thermal biology as other solitary insects, being heterothermic animals. However, honey bees exhibit unique thermal behaviors as eusocial insects; they maintain a brood nest temperature between $32^{\circ} \mathrm{C}$ and $36^{\circ} \mathrm{C}$, with an optimal temperature of $35^{\circ} \mathrm{C}$, to support the appropriate brood development (Seeley, 1995; Tautz et al., 2003). These results clearly demonstrate that honey bees are able to perceive fluctuations in nest temperature and respond with appropriate behaviors. Nevertheless, little is known regarding how honey bees sense the ambient temperatures, despite extensive investigations for almost 50 years (Heinrich, 1996). Electrophysiological and scanning electron microscope examinations of honey bee antennae have revealed that coelocapitular sensilla contain thermosensitive neurons (Yokohari et al., 1982; Yokohari, 1983). It has been shown that these sensilla are present in the flagellum; however, their role in honey bee thermosensation has not been reported to date.

To gain insight into the mechanism of honey bee thermosensation, we first screened for honey bee thermosensitive TRP channels and found that AmHsTRPA, a honey bee Hymenoptera-specific TRPA (HsTRPA), channel is activated by heat in a heterologous expression system. Hymenoptera contains the specific TRPA subfamily member HsTRPA that is absent in other 
insect orders. We showed previously that wasp (Nasonia vitripennis) HsTRPA was heat-activated and thus proposed that HsTRPA, originally created by the duplication of Wtrw, has gained the thermoresponsive property during evolution, which has resulted in the loss of TRPA1 in Hymenoptera (Matsuura et al., 2009). Characterization of AmHsTRPA and its physiological functions and evolution are discussed herein.

\section{Materials and Methods}

Construction of the AmHsTRPA-expressing vector for mammalian cells. Full-length AmHsTRPA cDNA was isolated by reverse transcriptase (RT)-PCR with honey bee brain total RNA and two primers, 5' -TAAATGCGGCCGCACCATGGACGATAAACAGATACACGAGAACTCCAC-3' and 5'-TCTATGACTAGTCTGTTATTCTTTTCCTTTGCCAGATTTTTCACAACA-3'. Bold letters indicate the initiation codon. The PCR product was cloned in the mammalian expression vector as described previously (Sokabe et al., 2008). The AmHsTRPA protein expressed by this construct is tagged with a V5 epitope at the C terminus and was used for initial screening of temperature sensitivity. A construct expressing untagged AmHsTRPA protein was then prepared using the above DNA construct as a template, the above primer with the initiation codon, and the primer 5'-GGCCCACTAGTCAGTTATTC-3'. This DNA construct was used for all of the experiments.

$\mathrm{Ca}^{2+}$ imaging experiments. For $\mathrm{Ca}^{2+}$ imaging, AmHsTRPA and DsRed-transfected human embryonic kidney (HEK) $293 \mathrm{~T}$ cells on cover glasses were incubated in culture medium containing $5 \mu \mathrm{M}$ Fura-2acetoxymethyl ester for $1-2 \mathrm{~h}$ at $33^{\circ} \mathrm{C}$. The cover glasses were washed with a standard bath solution containing (in mM) $140 \mathrm{NaCl}, 5 \mathrm{KCl}, 2 \mathrm{MgCl}_{2}, 2$ $\mathrm{CaCl}_{2}, 10$ HEPES, and 10 glucose at $\mathrm{pH} 7.4$, adjusted with $\mathrm{NaOH}$, and Fura-2 fluorescence was measured in a standard bath solution. The $\mathrm{Ca}^{2+}(-)$ bath solution containing (in $\mathrm{mm}$ ) $140 \mathrm{NaCl}, 5 \mathrm{KCl}, 2 \mathrm{MgCl}_{2}, 5$ EGTA, 10 HEPES, and 10 glucose, pH7.4, adjusted with $\mathrm{NaOH}$, was also used. The cover glasses were mounted in a chamber connected to a gravity flow system to deliver various stimuli and heated bath solutions. Thermal or chemical stimulation was applied by running a preheated and prechilled bath solution or a bath solution containing a chemical reagent. Data were acquired and analyzed as described previously (Sokabe et al., 2008).

Electrophysiology. For patch-clamp recording, $1 \mu \mathrm{g}$ of AmHsTRPA expression vector and $0.1 \mu \mathrm{g}$ of $\mathrm{pGreen}$ Lantern 1 vector were transfected to HEK293T cells cultured on 35-mm dishes using Lipofectamine Plus reagents. The standard bath solution containing $2 \mathrm{mM} \mathrm{CaCl}_{2}$ for the wholecell patch-clamp methods was the same as that used for the $\mathrm{Ca}^{2+}$ imaging experiments. The same solution was used as the pipette solution for inside-out patch-clamp recording. The $\mathrm{Ca}^{2+}(-)$ bath solution for whole-cell patch-clamp (used for dose-response analysis of camphor) was the same as the one used for $\mathrm{Ca}^{2+}$ imaging experiments. The $\mathrm{CsCl} /$ $\mathrm{Ca}^{2+}(-)$ pipette solution for the whole-cell patch-clamp and the bath solution for inside-out patch-clamp methods contained (in $\mathrm{mM}$ ) 140 $\mathrm{CsCl}, 5$ EGTA, and 10 HEPES at $\mathrm{pH}$ 7.4, adjusted with $\mathrm{CsOH}$. For the cation permeability experiments, the bath solutions contained (in $\mathrm{mm}$ ) $140 \mathrm{NaCl}$ (or $140 \mathrm{KCl}$ ), 10 glucose, and 10 HEPES at $\mathrm{pH} 7.4$, adjusted with $\mathrm{NaOH}$ (or $\mathrm{KOH}$ ) (for monovalent cations), or $110 \mathrm{MgCl}_{2}$ (or 110 $\left.\mathrm{CaCl}_{2}\right), 2 \mathrm{Mg}(\mathrm{OH})_{2}\left[\right.$ or $\left.2 \mathrm{Ca}(\mathrm{OH})_{2}\right], 10$ glucose, and 10 HEPES at $\mathrm{pH} 7.4$, adjusted with $\mathrm{HCl}$ (for divalent cations). Whole-cell recording data were sampled at $10 \mathrm{kHz}$ and filtered at $5 \mathrm{kHz}$ for analysis (Axopatch 200B amplifier with pClamp software; Molecular Devices). Inside-out patch recording data were sampled at $10 \mathrm{kHz}$ and filtered at $2 \mathrm{kHz}$ for analysis. The membrane potential was clamped at $-60 \mathrm{mV}$ in the whole-cell configuration and $+80 \mathrm{mV}$ in the inside-out configuration. Shift in liquid junction potential during heating $(\sim 2-4 \mathrm{mV})$ was corrected in the analysis. All of the patch-clamp methods were performed at room temperature except during the cold and heat stimulation experiments. For heat stimulation, a preheated solution was perfused with gravity by $2.5^{\circ} \mathrm{C} / \mathrm{s}$ near the thresholds, reaching a maximum of $40-46^{\circ} \mathrm{C}$. For cool stimulation, a prechilled solution in ice was used as described for the heat stimulation. In an inside-out patch clamp mode, heat was applied with a stage heater connected to a chamber (CC-28 and PH1; Warner Instru- ments) by $0.2^{\circ} \mathrm{C} / \mathrm{s}$ near the thresholds. The temperature was monitored with a thermocouple (TA-30; Warner Instruments) placed within 100 $\mu \mathrm{m}$ of the patch-clamped cell. Chemical stimulation was applied as described above for the $\mathrm{Ca}^{2+}$ imaging experiments. The current-voltage $(I-V)$ relationship during stimulation was obtained using voltage ramps $(-100$ to $+100 \mathrm{mV}$ in $500 \mathrm{~ms}$ ). Permeability ratios for the cations were calculated as described previously (Adams et al., 1980; Caterina et al., 1997). The permeability ratio for monovalent cations to Cs $\left(P_{\mathrm{X}} / P_{\mathrm{Cs}}\right)$ was calculated as follows: $P_{\mathrm{X}} / P_{\mathrm{Cs}}=\exp \left(\Delta V_{\text {rev }} F / R T\right)$, where $V_{\text {rev }}$ is the reversal potential, $F$ is Faraday's constant, $R$ is the universal gas constant, and $T$ is the absolute temperature. For measurement of divalent cation permeability, $P_{\mathrm{Y}} / P_{\mathrm{Cs}}$ was calculated as follows: $P_{\mathrm{Y}} / P_{\mathrm{Cs}}=3\left[\mathrm{Cs}^{+}\right]_{\mathrm{i}} \exp \left(\Delta V_{\text {rev }} F / R T\right)\left(1+\exp \left(\Delta V_{\text {rev }} F / R T\right)\right) /$ $4\left[\mathrm{Y}^{2+}\right]_{\mathrm{o}}$, where bracketed terms are activities. We assumed the activity coefficients were 0.75 for monovalent ions and 0.25 for divalent ions, which are included in the formula. The absolute current values were plotted on a log scale against the reciprocal of the absolute temperature ( $T$ ) (Arrhenius plot). $Q_{10}$ values were calculated from the slope of the linearly fitted lines in Arrhenius plots assuming that a slope is maintained up to $10^{\circ} \mathrm{C}$ higher from a flex point.

$R T-P C R$. Total RNA was isolated from the worker bee antennae, legs, proboscises, and wings and the brains of workers, males, and queen bees by using Trizol reagent. One microgram of total RNA was used for the RT reaction by using ReverTra Ace RT. The RT products were then used for PCR with Go TaqDNA polymerase and two primers, $5^{\prime}$-TGGCGATGTTCACTCACATAC-3' and 5'- GTGAACAGGATCTGTGAGCATACC- $3^{\prime}$. The resulting PCR products were sequenced to verify their identities.

Preparation of anti-AmHsTRPA antibody, immunostaining, and immunoprecipitation/Western blot. The DNA fragment encoding the N-terminal domain of AmHsTRPA (209 aa, 75-284) was PCR-amplified with two primers, 5'-AAGGATCCCCGCTCGCCAATCATGAGAAAAGAACCA-3' and 5'-AAGAATTCGGCTCCACGTAATCCAATTTCACGCCTG-3'. The PCR product was then cloned in pGEX6P-3 vector to synthesize the glutathione $S$-transferase (GST) fusion protein. The fusion protein was injected into a rabbit, and the anti-AmHsTRPA antibody was affinity-purified from the serum by using AmHsTRPA protein-conjugated Sepharose 4B.

AmHsTRPA-transfected HEK293T cells were processed for immunostaining as described previously (Matsuura et al., 2009). Rabbit antiAmHsTRPA antibody was used at 100-fold dilution.

The honey bee antennae, brains, proboscises, and legs were homogenized in RIPA buffer (150 mm NaCl, 1.0\% NP-40, 0.5\% deoxycholate, $0.1 \%$ SDS, 50 mм Tris-HCT, pH 8.0), and rabbit anti-AmHsTRPA antibody was added to the supernatants. The immunoprecipitates were recovered with Protein A-Sepharose beads, and then washed five times with RIPA buffer. The immunoprecipitation complexes and Drosophila S2 cells were suspended and directly homogenized with SDS-PAGE sample buffer (50 mu Tris-HCl, pH 6.8, 100 mm DTT, 2\% SDS, 0.1\% bromophenol blue, $10 \%$ glycerol), respectively. Western blot was then performed as described previously (Matsuura et al., 2009), and $10 \mu \mathrm{g}$ of GST-AmHsTRPA fusion protein prepared above was added to the primary antibody solution where indicated. Rabbit anti-AmHsTRPA antibody was used at 100 -fold dilution.

In situ hybridization. In situ hybridization of honey bee antenna sections with digoxigenin-labeled riboprobes was performed as described previously (Tsuchimoto et al., 2005). For preparation of the riboprobes, partial AmHsTRPA cDNA (amino acids 401-590) was cloned in pBluescript II, and then the sense and antisense riboprobes were prepared with either T7 or T3 RNA polymerase and ribonucleotide triphosphates containing digoxigenin-uridine-5' -triphosphate. Hybridization was performed overnight at $42^{\circ} \mathrm{C}$. High-stringency posthybridization washes were performed at the same temperature. Color development was monitored under a microscope and performed for the same periods on the samples hybridized with the sense and antisense riboprobes. The nuclei were simultaneously stained with 4',6-diamidino-2-phenylindole.

Thermotaxis assay of honey bees. To assay the temperature preference of honey bees, a temperature gradient of $28-48^{\circ} \mathrm{C}$ with a slope of $0.82^{\circ} \mathrm{C} / \mathrm{cm}$ was produced in an aluminum block $(27 \mathrm{~cm}$ long $\times 15 \mathrm{~cm}$ 

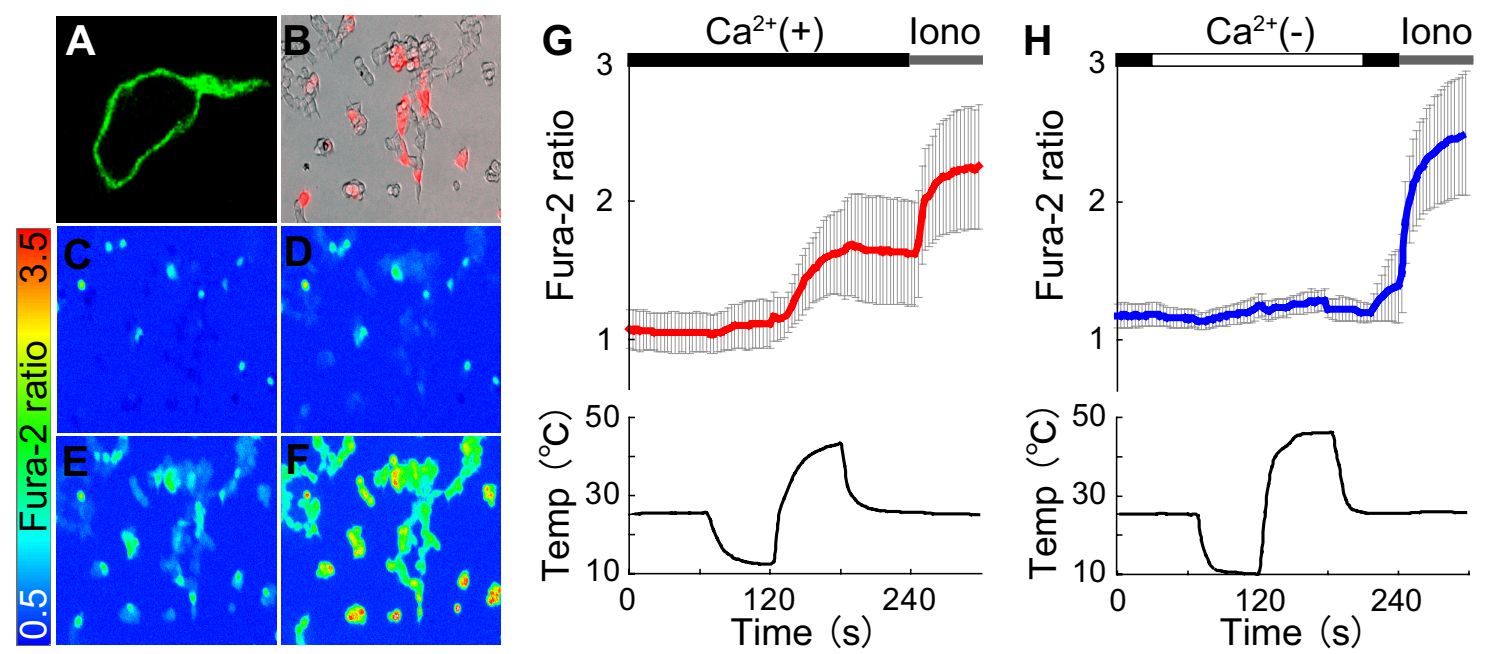

Figure 1. AmHsTRPA is a honey bee thermosensitive TRP channel. $\boldsymbol{A}$, Localization of AmHsTRPA expressed in HEK293 cells detected by immunostaining with an anti-AmHsTRPA antibody. $\boldsymbol{B}$, AmHsTRPA-expressing cells are identified using coexpressed DsRed protein. $\boldsymbol{C}-\boldsymbol{F}$, Representative results for Fura-2 $\mathrm{Ca}^{2+}$ imaging at $25.6^{\circ} \mathrm{C}(\boldsymbol{C}), 12.5^{\circ} \mathrm{C}(\boldsymbol{D})$, and $43.1^{\circ} \mathrm{C}(\boldsymbol{E})$ and in the presence of ionomycin $(5 \mu \mathrm{M})(\boldsymbol{F})$. The pseudocolor indicates intensity of the fluorescence ratio of $340 / 380 \mathrm{~nm}$. $\mathbf{G}$, Temporal changes in the Fura-2 ratio in AmHsTRPA-expressing cells (top) and temperature (bottom) in the presence of $2 \mathrm{~mm}$ extracellular $\mathrm{Ca}^{2+}, \mathrm{Ca}^{2+}(+)$. The average trace (red line) $\pm \mathrm{SD}$ is shown at the top. Ionomycin was added at $240 \mathrm{~s}$ (Iono, gray bar). $\boldsymbol{H}$, The same experiments as in $\mathbf{G}$ were performed in the absence of extracellular $\mathrm{Ca}^{2+}, \mathrm{Ca}^{2+}(-)$. The average trace (blue line) $\pm \mathrm{SD}$ is shown at the top.

wide $\times 2.5 \mathrm{~cm}$ high) as reported previously (Sayeed and Benzer, 1996). Thermometers were embedded in the block every $2.4 \mathrm{~cm}$, and the gradient was established using a cold circulating water chamber and a hot probe at each end. The aluminum block was covered with moist paper to maintain a uniform relative humidity along the gradient. This paper was divided into 20 observation fields with a black pencil for recording the distribution of honey bees. A glass plate with three separate lanes was placed $1.5 \mathrm{~cm}$ above the block, creating suitable corridors for honey bees to migrate. Seven to 10 honey bees per lane were placed between the aluminum block and the glass plate, allowed to migrate for $3 \mathrm{~h}$, and photographed every $10 \mathrm{~min}$ with a digital camera. The number of honey bees in the region corresponding to two adjacent observation fields (equivalent to the area between two thermometers) was counted in every photograph. The total number of honey bees in each region was divided by that of the entire area. Before introducing honey bees into the temperature gradient apparatus, they were placed in plastic vials and cooled on ice until they stopped moving. For the injection experiments, $1 \mu \mathrm{lof}$ Ringer's solution, $0.5 \mathrm{~mm}$ menthol, or $0.1 \mathrm{~mm}$ ruthenium red (RuR) solution was injected into their heads through small holes made between the two bases of the antennae by microcapillaries. For bilateral ablation of the flagellum, the flagella of the anesthetized bees were cut off by microscissors. All experiments were performed in a room where the temperature was kept constant at $25^{\circ} \mathrm{C}$.

Proboscis extension reflex assay of honey bees. A proboscis extension reflex (PER) assay is based on the observation that when starved honey bee antennae encounter a sugar substance the honey bee responds by extending its proboscis. The probability of extension increases with the sugar concentration and decreases with an increase in the concentrations of aversive-tasting substances in the sugar solution (de Brito Sanchez et al., 2005). The anesthetized bees prepared as above were harnessed in small tubes such that they could move only their antennae and mouthparts, including the proboscis. Honey bees were held in the dark under high humidity for $2 \mathrm{~h}$ to starve them. Each subject was checked for intact PER before beginning the experiments. Animals that did not show the reflex were discarded. Sucrose solution was carefully delivered to the tip of the antennae by means of a $1-\mathrm{ml}$ micropipette tip filled with a droplet of $10 \%$ sucrose solution containing either nothing, $3 \mathrm{~mm}$ camphor, $1 \mathrm{~mm}$ allyl isothiocyanate (AITC), $1 \mathrm{~mm}$ cinnamaldehyde (CA), $1 \mathrm{~mm}$ berberine, or $1 \mathrm{~mm}$ quinine. The same experiments were also performed in the presence of $10 \mu \mathrm{M}$ RuR. Hot sucrose solution was prepared by preheating $10 \%$ sucrose solution to $70^{\circ} \mathrm{C}$, and then immediately delivering it to the antennae as above. The temperature of the hot sucrose solution was therefore $45-50^{\circ} \mathrm{C}$ at the time of delivery. Menthol was added only to the room temperature and hot sucrose solutions, because it did not suppress chemical-evoked AmHsTRPA activation. All of the bees were lined up, and each bee was tested twice in sequential order with a 3- to 5-min interstimulus interval. The number of bees tested at one time was $10-20$ per test. The percentage of the population that responded in each test was calculated, and the averages were compared.

PER assay of Drosophila. UAS-DmTRPA1 and UAS-AmHsTRPA flies were generated by integrating the transgenes to 68A4 by a PhiC31 integrase-mediated recombination event (Bischof et al., 2007). These transgenes were driven by $\operatorname{trpA1-Gal4}$ under $\operatorname{trp} A 1^{1}$ background (Rosenzweig et al., 2005; Kwon et al., 2008). PER assay was performed basically as described by Kang et al. (2010). Two- to 4-day-old flies were starved overnight on wet cotton, anesthetized on ice, and affixed to a toothpick. Flies recovered in a humidified chamber for at least $2 \mathrm{~h}$ at room temperature before testing. Each subject was checked for intact PER before beginning the experiments. Animals that did not show the reflex were discarded. During the PER assay, the fly was first satiated with water, then a $100 \mathrm{~mm}$ sucrose solution containing nothing, $2 \mathrm{~mm}$ AITC, $2 \mathrm{~mm} \mathrm{CA}, 5$ $\mathrm{mm}$ camphor, or $10 \mathrm{~mm}$ aristolochic acid was touched to the forelegs with a pipette tip. If the proboscis was extended and contact with the sucrose solution was maintained for $3 \mathrm{~s}$, the response was scored as 1 . If the contact of proboscis was brief, a 0.5 was awarded. If the proboscis failed to contact the solution within $5 \mathrm{~s}$ of offering, a 0 was awarded. Each fly was offered compounds seven times per experiment, and between offerings water was given to satiation. Because AITC, CA, and camphor were accepted on first offering, PER frequency was calculated for the second through seventh offerings (sum of six scores per fly divided by six). Three groups of five to six flies per genotype were tested.

Statistical analysis. Data comparison was performed using Student's $t$ test. Multiple comparisons were performed using Tukey's method. Values are shown as means \pm SEM, unless indicated. A value of $p<0.05$ was considered significant.

\section{Results}

AmHsTRPA is a honey bee member of the HsTRPA channels activated by heat stimulation

AmHsTRPA expressed in HEK293 cells localizes primarily at the plasma membrane (Fig. $1 A$ ). Because many thermosensitive TRP channels show high permeability to $\mathrm{Ca}^{2+}$, we first performed $\mathrm{Ca}^{2+}$ imaging experiments by using Fura-2 to test whether AmHsTRPA increases intracellular $\mathrm{Ca}^{2+}$ concentration $\left(\left[\mathrm{Ca}^{2+}\right]_{\mathrm{i}}\right)$ with temperature changes. A robust $\left[\mathrm{Ca}^{2+}\right]_{\mathrm{i}}$ increase was ob- 
served in AmHsTRPA-expressing cells when temperature was raised above $30^{\circ} \mathrm{C}$, but not at lower temperatures $\left(\sim 10^{\circ} \mathrm{C}\right.$ ) (Fig. $1 B-G)$. The heat-evoked $\left[\mathrm{Ca}^{2+}\right]_{\mathrm{i}}$ increase was completely abolished in the absence of extracellular $\mathrm{Ca}^{2+}$ (Fig. $1 \mathrm{H}$ ), demonstrating that $\mathrm{Ca}^{2+}$ influxes from extracellular space through AmHsTRPA.

We then characterized the electrophysiological properties of AmHsTRPA expressed in HEK293 cells with a patch-clamp method. In the whole-cell configuration, AmHsTRPA showed transient inward currents upon temperature increase from $15^{\circ} \mathrm{C}$, but not decrease from $25^{\circ} \mathrm{C}$, at a holding potential of $-60 \mathrm{mV}$, indicating heat responsiveness of the channel (Fig. $2 \mathrm{~A}$ ). The currents developed when the temperature was raised to $40^{\circ} \mathrm{C}$, and then deactivated under constant heat stimulation (Fig. $2 A, B$ ). Heat-evoked current activation was not observed in mocktransfected HEK293 cells (data not shown), suggesting that the currents are specifically mediated through AmHsTRPA. AmHsTRPA showed desensitization during the repeated heat application, and the channels were still inactivated even after long time recovery at $25^{\circ} \mathrm{C}$ (supplemental Fig. 1, available at www. jneurosci.org as supplemental material). Similar heat-evoked channel activation was also observed with a wasp HsTRPA, NvHsTRPA (Matsuura et al., 2009), confirming HsTRPA as a new thermosensitive TRP channel subtype. A temperature profile of AmHsTRPA activation showed that the current gradually began to develop above $24^{\circ} \mathrm{C}$, followed by large transient currents toward $40^{\circ} \mathrm{C}$ (Fig. $2 \mathrm{~B}, \mathrm{C}$ ). An Arrhenius plot showed a flex point at $24.1 \pm 0.8^{\circ} \mathrm{C}$, and the mean $Q_{10}$ value was slightly shifted from $1.4 \pm 0.1$ to $3.3 \pm 0.3(n=8)$ (Fig. $2 D)$ at this temperature. However, $Q_{10}$ values $\sim 1-3$ are seen in general enzymes and other ion channels (Hille, 2001) and are considerably lower than those of known thermosensitive TRP channels $\left(Q_{10}>10\right)$ (Sokabe et al., 2008). Notably, an Arrhenius plot showed the second flex point at $33.5 \pm 0.7^{\circ} \mathrm{C}$, and the mean $Q_{10}$ value shifted to $7.1 \pm 1.4$ $(n=8)$ (Fig. $2 \mathrm{D})$, which was much higher than that at $24^{\circ} \mathrm{C}$. Because the temperatures inside honey bee hives are usually higher than $30^{\circ} \mathrm{C}$ (Kronenberg and Heller, 1982; Fahrenholz et al., 1989), we attempted to measure the current activation of AmHsTRPA after preheating to $30^{\circ} \mathrm{C}$. An AmHsTRPA-expressing cell was held at $30^{\circ} \mathrm{C}$ in a heating chamber after a whole-cell mode was achieved, and then stimulated with higher heat by using a perfusing prewarmed bath solution (Fig. 2E,F). Under these conditions, a robust current was again generated at $\sim 34^{\circ} \mathrm{C}$ (Fig. 2G). Consistent with these results, the Arrhenius plot displays an explicit flex point at $33.9 \pm 0.6^{\circ} \mathrm{C}(n=10)($ Fig. $2 H)$, which was almost identical to the temperature of a second flex point obtained when the cell was stimulated from $15^{\circ} \mathrm{C}$ (Fig. $2 \mathrm{D}$ ). The mean $Q_{10}$ value increased to $17.2 \pm 4.0$ above the flex point, which is comparable with those of known thermosensitive TRP channels. Thus, we defined this temperature $\left(33.9 \pm 0.6^{\circ} \mathrm{C}\right)$ as a primary temperature threshold for AmHsTRPA activation. To test whether AmHsTRPA is directly activated by heat, we tried to obtain the heat activation currents at the single-channel level. In an inside-out patch-clamp configuration, single-channel currents were observed during heating, and its chord conductance at $+80 \mathrm{mV}$ was as small as $14.7 \pm 0.9$ picosiemens $(\mathrm{pS})(n=9)$ (Fig. $2 I$ ). We therefore conclude that AmHsTRPA is a heat-sensitive ion channel activated around the optimal brood nest temperature.

\section{Activation of AmHsTRPA is modulated by chemical compounds}

It has been shown that mammalian thermosensitive TRP channels are not only activated by heat but also by various compounds
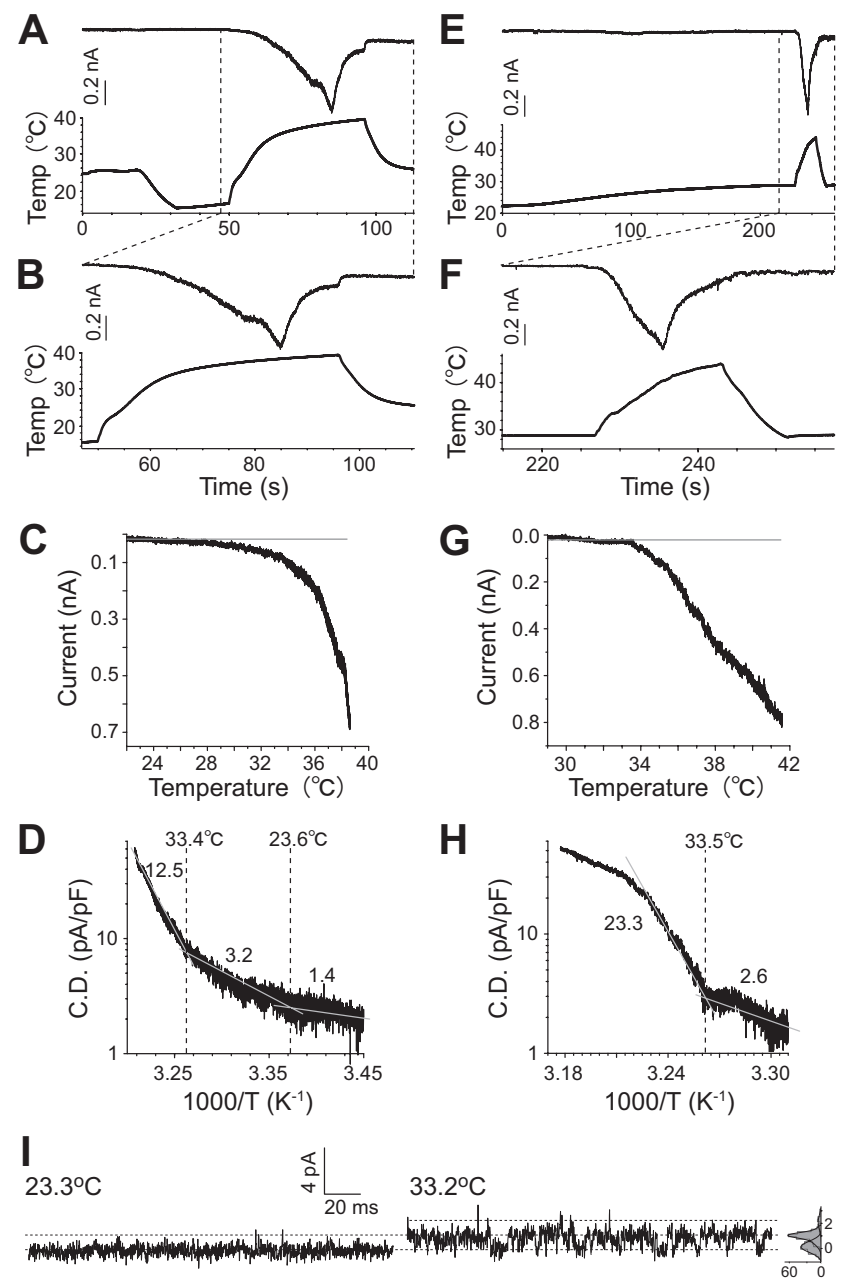

Figure 2. AmHsTRPA is activated by heat $>34^{\circ} \mathrm{C}$. $A$, Temporal changes in the current (top trace) in an AmHsTRPA-expressing cell and temperature (bottom trace) during temperature fluctuation. $\boldsymbol{B}$, Expanded traces from $\boldsymbol{A}$ show the activation profile of AmHsTRPA during heating from $15^{\circ} \mathrm{C}$. C, A representative temperature-response profile for heat-evoked AmHsTRPA current, as observed in $\boldsymbol{B}$. The solid horizontal line indicates the basal level. $\boldsymbol{D}$, An Arrhenius plot for the heat-evoked AmHsTRPA current shows dual flex points on temperature dependency. Data in $\boldsymbol{B}$ were converted. The crossing points of the three linearly fitted lines indicated as solid red lines (flex points) show changes in the temperature dependency of AmHsTRPA at $23.6^{\circ} \mathrm{C}$ and $33.4^{\circ} \mathrm{C}$ in this example. The $Q_{10}$ value was calculated for each line (see Materials and Methods). $\boldsymbol{E}$, Temporal changes in the AmHsTRPA current (top trace) and temperature (bottom trace) during slow heating (up to $29^{\circ} \mathrm{C}$ ), followed by fast heating. $\boldsymbol{F}$, Expanded traces from $\boldsymbol{E}$ show the activation profile of AmHsTRPA during fast heating from $29^{\circ} \mathrm{C}$. $\boldsymbol{G}$, A representative temperatureresponse profile for heat-evoked AmHsTRPA current, as observed in $\boldsymbol{F}$. The solid horizontal line indicates the basal level. $\boldsymbol{H}$, An Arrhenius plot for the heat-evoked AmHsTRPA current shown in $\boldsymbol{F}$ demonstrates a clear flex point for temperature dependency. The intersection of the two linearly fitted lines (a flex point) was defined as a primary temperature threshold for AmHsTRPA activation, which was $33.5^{\circ} \mathrm{C}$ in this example. Note that this temperature is quite similar to that of the second flex point in $\boldsymbol{D}$. The $Q_{10}$ for each line is also shown. $\boldsymbol{I}$, Single-channel currents in AmHsTRPA-expressing excised membrane without (left) or with (right) heat stimulation in an inside-out patch-clamp mode at $+80 \mathrm{mV}$ holding potential. The dotted lines indicate the closed- and opened-channel levels. Amplitude histograms (gray bars) during heat application are shown at the far right. $x$ and $y$ axes indicate event numbers per $400 \mathrm{~ms}$ and amplitude (pA), respectively. Histograms were drawn with a bin width of 0.2 nanoampere $(\mathrm{nA})$ and fitted with a Gaussian function. The averaged unitary amplitude was $1.18 \pm 0.07 \mathrm{pA}(n=9)$.

(Clapham, 2007). We thus attempted to identify chemical compounds either activating or inhibiting AmHsTRPA. First, candidate activators of AmHsTRPA were screened through $\mathrm{Ca}^{2+}$ imaging experiments. Among the mammalian TRPA1 activators, AITC and CA, both of which are known to covalently modify 

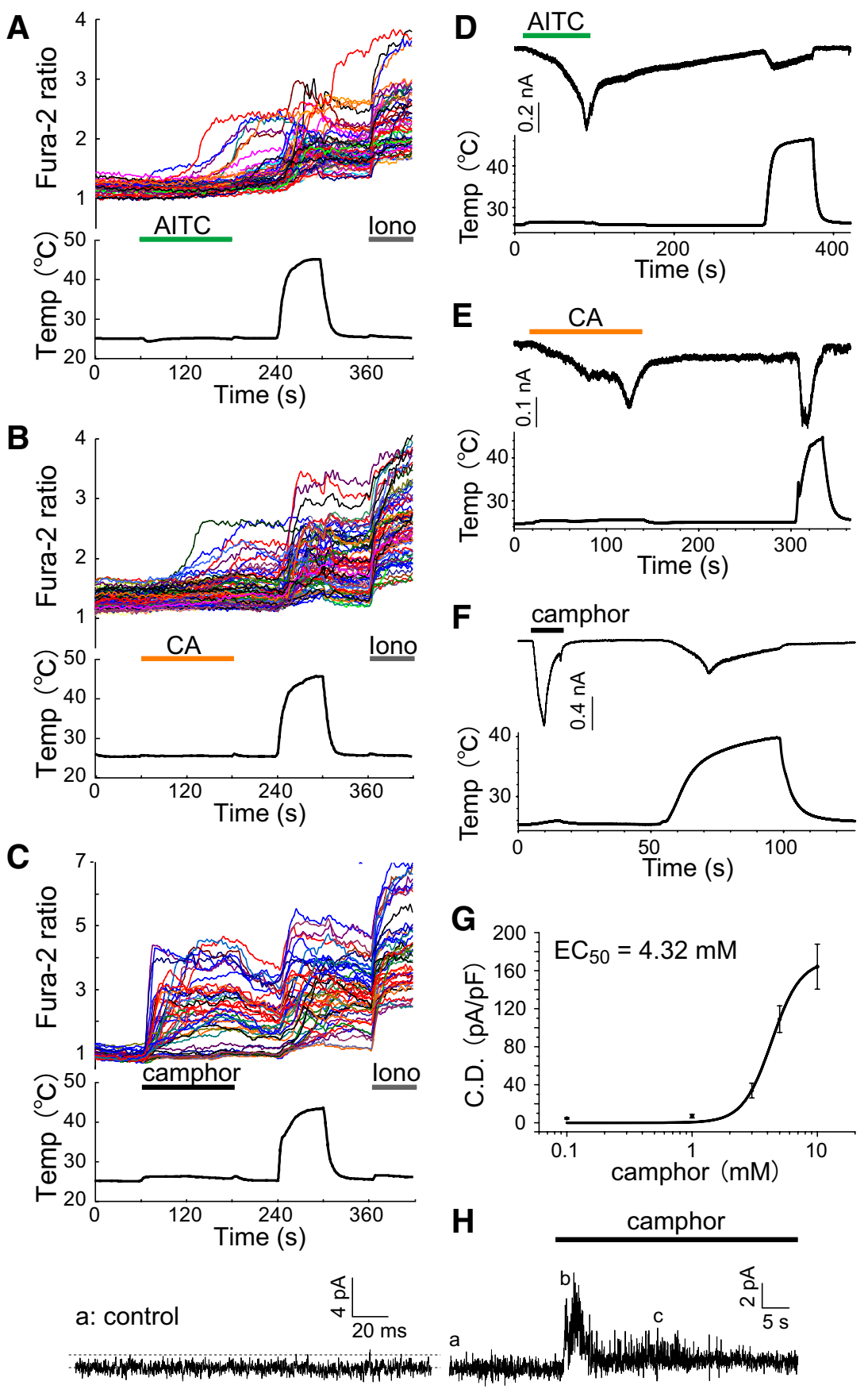

b: transient state

c: sustained state

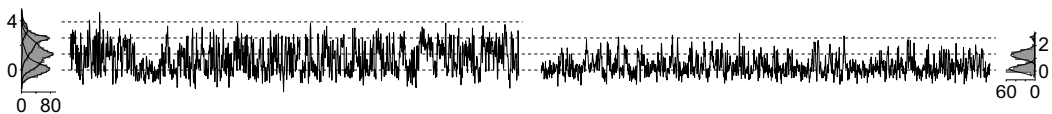

Figure 3. AmHsTRPA is activated by chemical compounds. $A-C$, Temporal changes in the Fura-2 ratio in AmHsTRPA-expressing cells (top traces) and temperature (bottom traces) during AITC $(\boldsymbol{A}), \mathrm{CA}(\boldsymbol{B})$, or camphor $(\boldsymbol{C})$ application in the presence of $2 \mathrm{~mm}$ extracellular $\mathrm{Ca}^{2+}$. The traces from individual cells indicated with various colors are shown at the top. AITC (1 mM) was added at $60-180 \mathrm{~s}(\boldsymbol{A}$, green bar), and ionomycin was added at $360 \mathrm{~s}$ (iono, gray bars). The same experiments were also performed with 1 mm CA ( $\boldsymbol{B}$, vermilion bar) and $5 \mathrm{~mm}$ camphor ( $\boldsymbol{C}$, black bar). $\boldsymbol{D}-\boldsymbol{F}$, Temporal changes in the current (top trace) in AmHsTRPAexpressing cells and temperature (bottom trace) during treatment with $1 \mathrm{~mm}$ AITC (D), $1 \mathrm{~mm} C A(\boldsymbol{E})$, or $5 \mathrm{~mm}$ camphor $(\boldsymbol{F})$ in a whole-cell patch-clamp mode. Note that inactivation required a long time and partial activity usually remained after stimulation with AITC $(\boldsymbol{D})$ or $C A(\boldsymbol{E})$. In contrast, the response to camphor $(\boldsymbol{F})$ was much faster and larger than those to AITC or CA. $\boldsymbol{G}$, The dose-response profile of camphor for AmHsTRPA activation. Maximum values for the current density were obtained and fitted to Hill plots $(n=8-12)$. Higher concentrations of camphor $(>10 \mathrm{~mm})$ were not tested because of solubility. $\boldsymbol{H}$, Single-channe currents in AmHsTRPA-expressing excised membrane during $10 \mathrm{~mm}$ camphor application in an inside-out patch-clamp mode at $+80 \mathrm{mV}$ holding potential. Note that the integrative currents of single-channel openings resemble the transient currents in intracellular cysteine residues (Hinman et al., 2006; Macpherson et al., 2007), activated AmHsTRPA (Fig. $3 A, B$ ); however, other TRPA1 agonists such as acrolein, nicotine, nifedipine, menthol, and TRP channel agonists failed to activate the channel (see supplemental Fig. 2, available at www.jneurosci.org as supplemental material). Meanwhile, camphor, an inhibitor of mammalian TRPA1 (Xu et al., 2005), robustly activated AmHsTRPA (Fig. 3C). The effects of these compounds on AmHsTRPA were further tested using a patch-clamp method. Currents developed slowly by addition of AITC and CA followed by slow inactivation after washout in AmHsTRPA-expressing HEK293 cells (Fig. 3D,E). These currents were AmHsTRPA-dependent because the same cells responded to heat stimulation. Nevertheless, AmHsTRPA activation needs relatively higher doses of these activators compared with those for mammalian TRPA1. AITC-evoked current densities were $2.1 \pm 0.4$ picoamperes per picofarad $(\mathrm{pA} / \mathrm{pF})(0.1 \mathrm{~mm} ; n=6)$ and $13.7 \pm 1.8$ $\mathrm{pA} / \mathrm{pF}(1 \mathrm{~mm} ; n=5)$, and CA-evoked current densities were $1.2 \pm 0.9 \mathrm{pA} / \mathrm{pF}(0.1$ $\mathrm{mm} ; n=4)$ and $11.5 \pm 1.6 \mathrm{pA} / \mathrm{pF}(1 \mathrm{~mm}$; $n=5)$. Meanwhile, addition of camphor generated a rapid and large current, and it was then quickly inactivated (Fig. $3 F$ ). The desensitization was also observed during repeated camphor application as repeated heat stimulation (supplemental Fig. 1, available at www.jneurosci.org as supplemental material). The dose-response analysis for camphor indicated that the $\mathrm{EC}_{50}$ for AmHsTRPA activation was $4.3 \pm 0.2 \mathrm{~mm}$ with a Hill coefficient of 3.8 (Fig. 3G). Camphor-evoked single-channel currents were observed in an inside-out patch-clamp configuration, and its chord conductance at $+80 \mathrm{mV}$ was $14.8 \pm 0.4 \mathrm{pS}$ $(n=7)$ (Fig. $3 H)$, which was similar to the value obtained by heat stimulation (Fig. 2I). These results suggest that AmHsTRPA is a receptor for these herbal compounds.

We also tested the effects of several known inhibitors of TRP channels on AmHsTRPA activation and found that RuR

$\leftarrow$

whole-cell configuration in $\boldsymbol{F}$. Basal $(\boldsymbol{a})$, transient $(\boldsymbol{b})$, and sustained $(\boldsymbol{c})$ states are magnified from corresponding lines in the top right trace. The dotted lines indicate the closed- and opened-channel levels. Amplitude histograms (gray bars) during camphor application are shown in the far left (for $\boldsymbol{b}$ ) and the far right (for $c$ ). $x$ and $y$ axes indicate event numbers per $400 \mathrm{~ms}$ and amplitude (pA), respectively. Histograms were drawn with a bin width of $0.2 \mathrm{nA}$ and fitted with a Gaussian function. The averaged unitary amplitude was $1.19 \pm 0.03 \mathrm{pA}$ $(n=8)$. 
(a broad inhibitor of TRP channels including mammalian TRPA1) and menthol (an activator of human TRPA1 and an activator and inhibitor of mouse TRPA1 at low and high concentrations, respectively) (Xiao et al., 2008) inhibit AmHsTRPA activation by heat stimulation (Fig. $4 A-C$ ). RuR significantly reduced heat-evoked AmHsTRPA activation (control: $41.8 \pm$ $6.7 \mathrm{pA} / \mathrm{pF}, n=15 ; 1 \mu \mathrm{M}$ RuR: $8.4 \pm 1.6$ $\mathrm{pA} / \mathrm{pF}, n=11)$. A low concentration of menthol (100 nM) blocked heat-evoked currents to approximately half of the maximum activation (Fig. 4C). Inhibition of heat-evoked current activation either by RuR or menthol was reversible. To test whether RuR suppresses AmHsTRPA activation by AITC, CA, or camphor, $10 \mu \mathrm{M}$ RuR was added immediately after the maximum activation of AmHsTRPA. We used this method because it was often difficult to completely remove RuR by washing out. The currents generated by AITC, $\mathrm{CA}$, or camphor quickly returned to baseline in the presence of RuR (Fig. 4D-F). These current profiles were obviously different from those obtained without RuR treatment (see supplemental Fig. 3, available at www.jneurosci.org as supplemental material for camphor). RuR thus inhibits AmHsTRPA activation by AITC, CA, and camphor and heat stimulation. The effects of menthol on chemical activation of AmHsTRPA were also examined by using the same protocol as that used for the RuR treatments. Interestingly, none of the chemical-induced current activations was inhibited by $100 \mu \mathrm{M}$ menthol treatment, as opposed to RuR ( 3 mM camphor: $43.9 \pm 5.6$ $\mathrm{pA} / \mathrm{pF}, n=6$; camphor with $100 \mu \mathrm{M}$ menthol: $43.8 \pm 5.8 \mathrm{pA} / \mathrm{pF}, n=6$, not significant) (Fig. 4G-I). We also tested another TRPA1 blocker, HC-030031 (Eid SR et al., 2008); however, it did not affect both heat-and chemical-evoked activation of AmHsTRPA (supplemental Fig. 3, available at www.jneurosci. org as supplemental material). These results indicate that the activation mechanism of AmHsTRPA by chemical compounds is different from that by heat stimulation. The chemical sensitivity of AmHsTRPA is unique but shares some common properties with mammalian TRPA1.

\section{The ion selectivity of AmHsTRPA differs between heat and chemical stimulations}

Because AmHsTRPA appeared to have different channel properties when activated by heat or chemical stimulation (based on the observed difference in sensitivity to menthol), we expected that the ion permeability of AmHsTRPA might be different between heat and chemical activation. The $I-V$ relationship of AmHsTRPA upon heat stimulation showed dual rectification with slight positive reversal potentials of $5.4 \pm 1.5 \mathrm{mV}(n=6)$ (Fig. $5 A)$, suggesting that the channel had low selectivity for cations. The $I-V$ relationship of AmHsTRPA-mediated current evoked by addition of camphor, AITC, or CA showed dual rectification with more positive reversal potentials than that observed with heat stimulation (Fig. $5 B-D)(20.6 \pm 1.5 \mathrm{mV}$ for camphor, $n=8 ; 23.3 \pm 4.0 \mathrm{mV}$ for AITC, $n=5$; and $23.1 \pm 3.5 \mathrm{mV}$ for CA, $n=5$ ). These results suggest that the ion selectivity of AmHsTRPA gated by chemical compounds is different from that induced by heat stimulation. To address this possibility, we measured reversal potentials in various extracellular monovalent or divalent cation solutions with a $\mathrm{CsCl}$ pipette solution (Fig. $5 E, F$ ). The calculated relative permeabilities demonstrated that heat-activated AmHsTRPA was slightly more permeable to $\mathrm{Mg}^{2+}$ and $\mathrm{Ca}^{2+}$ than to $\mathrm{Na}^{+}$, $\mathrm{K}^{+}$, or Cs ${ }^{+}$(Fig. $\left.5 E, G\right)\left(\mathrm{Na}^{+} / \mathrm{K}^{+} / \mathrm{Cs}^{+} / \mathrm{Mg}^{2+} / \mathrm{Ca}^{2+}=1.0: 0.86\right.$ : $0.86: 2.15: 1.52)$. During camphor stimulation, however, the reversal potentials obtained with extracellular $\mathrm{MgCl}_{2}$ and $\mathrm{CaCl}_{2}$ showed distinct shifts to positive potentials, and the calculated relative permeabilities demonstrated that camphor-activated AmHsTRPA was much more permeable to $\mathrm{Mg}^{2+}$ and $\mathrm{Ca}^{2+}$ than to $\mathrm{Na}^{+}, \mathrm{K}^{+}$, or Cs ${ }^{+}$(Fig. $\left.5 \mathrm{~F}, \mathrm{G}\right)\left(\mathrm{Na}^{+} / \mathrm{K}^{+} / \mathrm{Cs}^{+} / \mathrm{Mg}^{2+} / \mathrm{Ca}^{2+}=\right.$ 

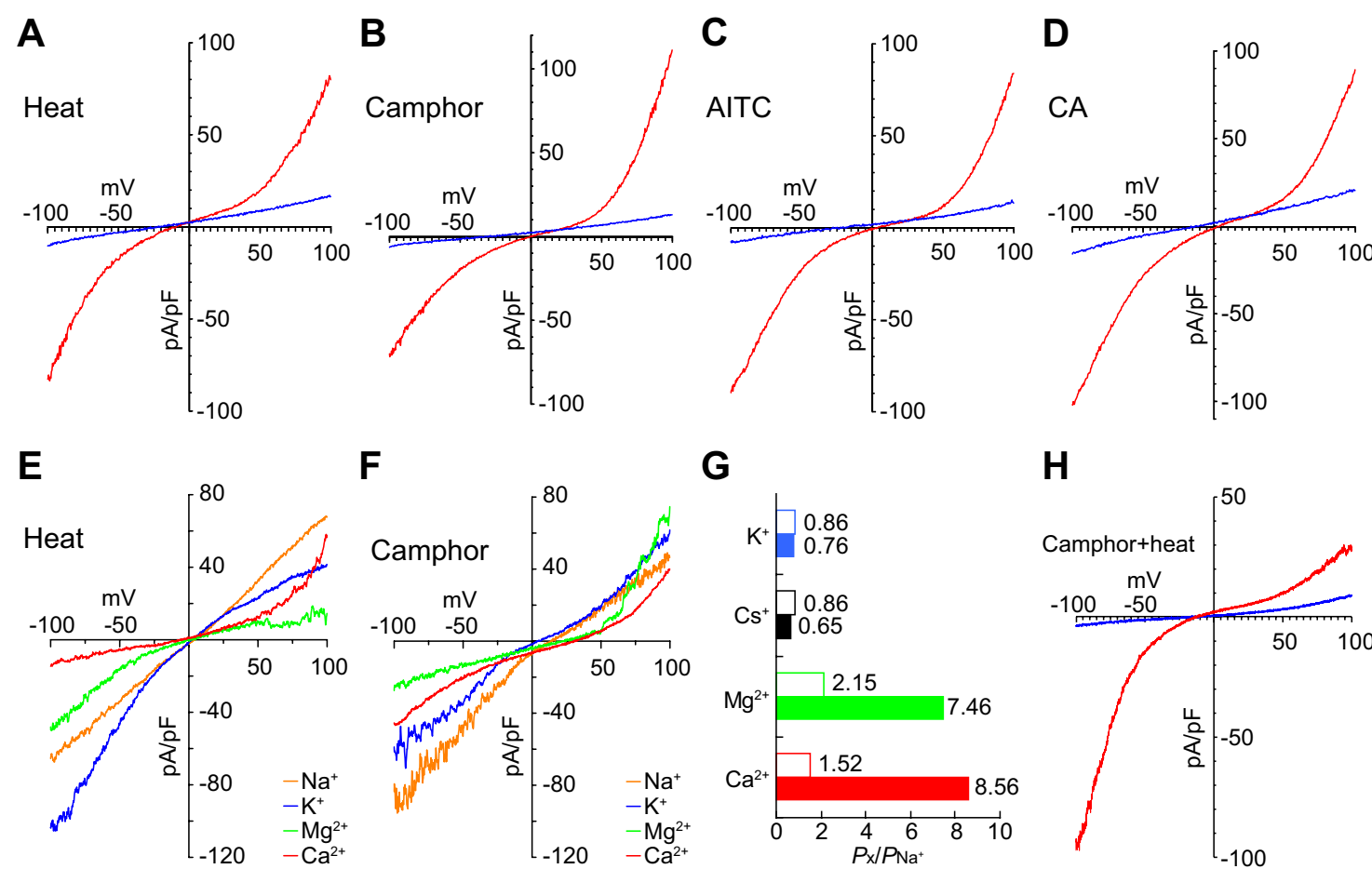

$\mathbf{F}$

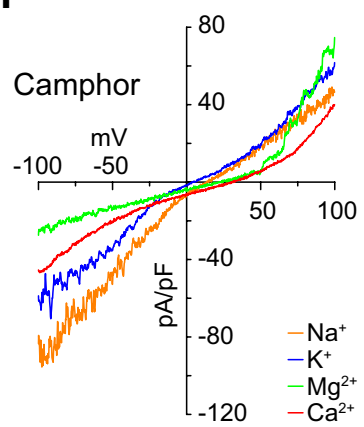

G

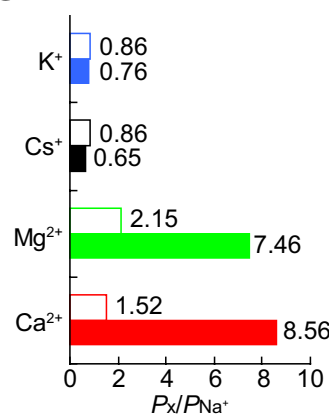

H

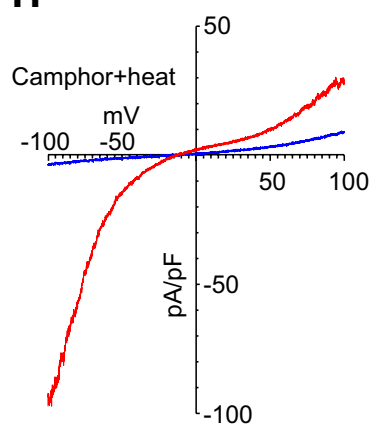

Figure 5. Heat- and chemical-induced gating of AmHsTRPA demonstrate different ion permeabilities. $\boldsymbol{A}-\boldsymbol{D}$, Representative $I-V$ relationships for AmHsTRPA activation with heat $(\boldsymbol{A}), 5 \mathrm{~mm}$ camphor $(\boldsymbol{B}), 1 \mathrm{~mm}$ AITC $(\boldsymbol{C})$, or $1 \mathrm{~mm} C A(\boldsymbol{D})$. Blue and red traces indicate control $\left(15^{\circ} \mathrm{C}\right.$ in $\left.\boldsymbol{A}\right)$ and activation states, respectively. Heat-dependent shifts in the liquid junction potentials $\left(\Delta \mathrm{JP}_{\mathrm{H}}\right)$ were not corrected in the plots. $\boldsymbol{E}, \boldsymbol{F}, I-V$ relationships for AmHsTRPA activation with heat $(\boldsymbol{E})$ or $5 \mathrm{~mm}$ camphor $(\boldsymbol{F})$ measured with $\mathrm{NaCl}, \mathrm{KCl}, \mathrm{MgCl}_{2}$, or $\mathrm{CaCl}_{2}$ bath solutions and a $\mathrm{CSCl}$ pipette solution. For heat activation, the reversal potential for each cation solution was $4.2 \pm 0.9 \mathrm{mV}(\mathrm{NaCl} ; n=6), 0.2 \pm 1.4 \mathrm{mV}(\mathrm{KCl} ; n=5), 5.2 \pm 2.2 \mathrm{mV}\left(\mathrm{MgCl}_{2} ; n=5\right)$, or $-1.0 \pm 1.0 \mathrm{mV}\left(\mathrm{CaCl}_{2} ; n=6\right)$. For camphor activation, the reversal potential for each cation solution was $11.8 \pm 1.3 \mathrm{mV}(\mathrm{NaCl} ; n=6), 4.4 \pm 0.8 \mathrm{mV}(\mathrm{KCl} ; n=5), 30.1 \pm 2 \mathrm{mV}(\mathrm{MgCl} ; n=5)$, or $32.2 \pm 3 \mathrm{mV}\left(\mathrm{CaCl}_{2} ; n=5\right)$. Basal traces were subtracted in $\boldsymbol{E}$ and $\boldsymbol{F}$, but $\Delta \mathrm{JP}_{\mathrm{H}}$ values were not compensated for in $\boldsymbol{E}$. $\boldsymbol{G}$, Relative permeability ratios of K ${ }^{+}, \mathrm{CS}^{+}, \mathrm{Mg}^{2+}$, and $\mathrm{Ca}^{2+}$ to Na ${ }^{+}$of AmHsTRPA activated by heat (open bars) or $5 \mathrm{~mm}$ camphor (solid bars) are shown after compensating for $\Delta \mathrm{JP}_{\mathrm{H}}$ values of the reversal potentials $(n=5-6)$. $\boldsymbol{H}$, A representative $/-V$ relationship for AmHsTRPA activation by heated camphor $(0.5 \mathrm{~mm})$. Camphor solution was warmed for $<5 \mathrm{~min}$ just before the experiments to minimize evaporation and/or degradation. Blue and red traces were obtained from control $\left(15^{\circ} \mathrm{C}\right)$ and activation states, respectively. $\Delta J P_{H}$ were not corrected in the plots.

1.0:0.76:0.65:7.46:8.56). These results, together with menthol sensitivity, suggest that the gating mechanisms of AmHsTRPA are different between heat and chemical stimulations. We then tested whether heat and camphor have a synergistic effect. AmHsTRPA-expressing cells were pretreated with $0.5 \mathrm{~mm}$ camphor, which does not evoke current activation (see Fig. $3 G$ ), and stimulated with heated solution containing $0.5 \mathrm{~mm}$ camphor. The averaged current density was $41.8 \pm 3.6 \mathrm{pA} / \mathrm{pF}(n=13)$, which was equivalent to the heat-evoked current density (41.8 \pm $6.7 \mathrm{pA} / \mathrm{pF} ; n=15)$. The temperature dependency, however, lost its flex points in an Arrhenius plot. Thus, we were not able to calculate the temperature threshold for camphor/heat dual activation (data not shown). The $I-V$ relationship displayed a strong inward rectification with slight negative reversal potentials of $-6.4 \pm 2 \mathrm{mV}(n=7)$ (Fig. $5 H)$. It indicates that the $I-V$ relationship of camphor/heat dual stimulation is different from that in either heat or camphor stimulation alone, and the channel showed relatively low selectivity for cations as heat stimulation. Thus, AmHsTRPA has multiple gating modes depending on the types and combination of stimuli.

\section{AmHsTRPA is expressed in a few discrete cells of the antennal flagellum}

To gain insight into the physiological functions of AmHsTRPA, we first characterized its expression profile in honey bees. AmHsTRPA mRNA was expressed in the antennae, legs, proboscises, and brains of worker bees (Fig. $6 A, B$ ). It was also expressed in the brains of male (drone) and queen bees (Fig. $6 B$ ), demon- strating that AmHsTRPA is ubiquitously expressed in all castes. Consistent with its mRNA expression, AmHsTRPA protein was also detected in the above tissues by immunoprecipitation followed by Western blot (Fig. 6C). Its molecular mass is $110 \mathrm{kDa}$, which is comparable to that of AmHsTRPA expressed in Drosophila S2 cells. These bands disappeared when GST-AmHsTRPA fusion protein was present during the incubation of blot with anti-AmHsTRPA antibody, indicating that the antibody is specific to AmHsTRPA. In situ hybridization was performed to localize the AmHsTRPA-expressing cells in the antennae because thermosensitive neurons are present in the coelocapitular sensilla of the antennae (Yokohari et al., 1982; Yokohari, 1983). A few discrete cells expressing AmHsTRPA were present in the flagellum (Fig. 6D-F), but not in the scape or the pedicel (supplemental Fig. 4, available at www.jneurosci.org as supplemental material). For example, two and one discrete AmHsTRPAexpressing cells were present in the 10th and ninth flagellar segments, respectively (Fig. 6D,E). Observations with higher magnification indicated that the positive signal appeared to be present in the cytoplasm of large soma of the sensory neuron beneath the cuticle (Fig. 6 F). The sense probe did not give significant signal (Fig. $6 \mathrm{G}, \mathrm{H}$ ). Immunostaining of the antennal sections with anti-AmHsTRPA antibody was not successful. The number and localization of AmHsTRPA-expressing neurons appear to be consistent with those of the coelocapitular sensilla where both hygrosensitive and thermosensitive neurons are present (Yokohari et al., 1982; Yokohari, 1983; Nishino et al., 2009). Nevertheless, we were not able to confirm colocalization 
A

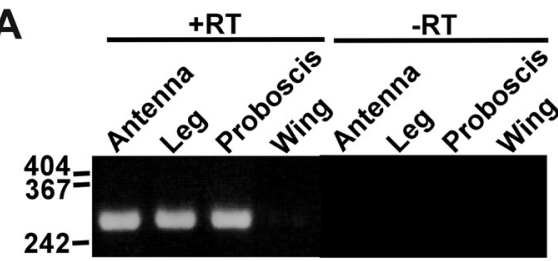

B
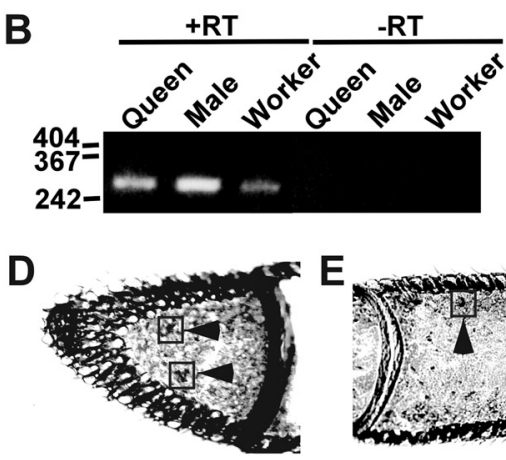

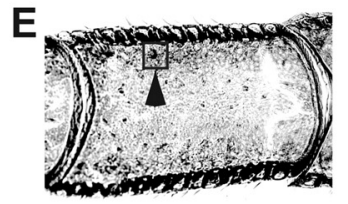

C
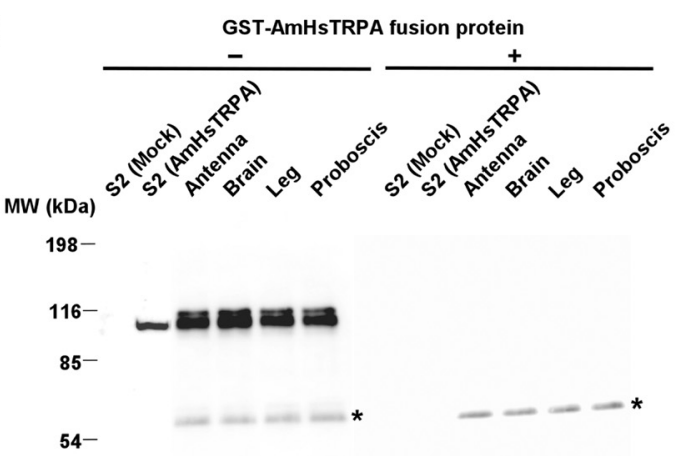

$37-$

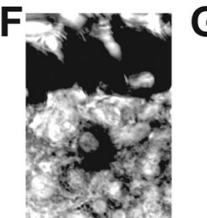

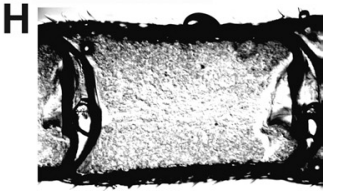

Figure 6. AmHsTRPA is expressed in the appendages and the brain. $\boldsymbol{A}$, Expression of AmHSTRPA mRNA in the antennae, legs, proboscises, and wings of worker bees. $\boldsymbol{B}$, Expression of AmHsTRPA mRNA in the brains of queens, males (drones), and worker bees. PCR-amplified products of 271 bp were detected with RNA samples treated with RT (+RT) but not without it ( - RT). C, Expression of AmHsTRPA protein in the antennae, brains, proboscises, and legs of worker bees. As controls, the extracts of mock- and AmHsTRPA-transfected Drosophila S2 cells, S2 (Mock) and S2 (AmHsTRPA), were also analyzed. Honey bee samples were analyzed by immunoprecipitation followed by Western blot, and the bands indicated by asterisks are lg heavy chain used for immunoprecipitation. The 110-kDa proteins were detected in the absence $(-)$ but not the presence $(+)$ of GST-AmHsTRPA fusion protein, indicating that they correspond to AmHsTRPA. Molecular mass markers are shown on the left. $\boldsymbol{D}, \boldsymbol{E}$, AmHsTRPA-expressing cells (squares with arrowheads) in the 10th $(\boldsymbol{D})$ and ninth $(\boldsymbol{E})$ segments of the flagellum were detected by in situ hybridization with an antisense probe. $\boldsymbol{F}$, Higher-magnification view of the region indicated by a black square in $\boldsymbol{E}$. $\boldsymbol{G}, \boldsymbol{H}$, The sense probe did not give the significant signals for the 10 th $(\boldsymbol{G})$ or ninth $(\boldsymbol{H})$ segments of the flagellum.

of the AmHsTRPA-expressing neurons and the coelocapitular sensilla through in situ hybridization because of a lack of the specific marker.

Ablation of the antennal flagella and injection of AmHsTRPA inhibitors impair warmth avoidance of honey bees

It is well known that the temperature of the brood nest is regulated near $35^{\circ} \mathrm{C}$ to support optimal development of the eggs, larvae, and pupae (Kronenberg and Heller, 1982; Fahrenholz et al., 1989; Seeley, 1995). Furthermore, in a laboratory experiment, it was shown that a group of 10-20 honey bees preferred temperatures of $27-33^{\circ} \mathrm{C}$ when placed in a temperature gradient $(10-$ $50^{\circ} \mathrm{C}$ ) chamber (Grodzicki and Caputa, 2005). When we measured the thermotaxis of honey bees on an aluminum block with a temperature gradient of $28-48^{\circ} \mathrm{C}$, they were found to prefer temperatures of $34-35^{\circ} \mathrm{C}$ (Fig. $7 A$ ), similar to the results of the previous studies mentioned above. To suppress AmHsTRPA activation by heat stimulation, we injected Ringer's solution (control), RuR, or menthol into the head between the two bases of the antennae. RuR and menthol circulate in both the brain and the antennae under these conditions, allowing AmHsTRPA activation to be inhibited in these regions. The thermotaxis behavior of the control bees injected with Ringer's solution was comparable with that of the untreated bees; however, those injected with either $0.1 \mathrm{~mm}$ RuR or $0.5 \mathrm{~mm}$ menthol tended to select regions with warmer temperatures than the control bees (Fig. $7 A, B$ ). The peak temperatures selected by the RuR- and menthol-injected honey bees were $37^{\circ} \mathrm{C}$ and $39^{\circ} \mathrm{C}$, respectively (Fig. 7A). Bilateral ablation of the antennal flagella also resulted in an increase of the fraction of honey bees in hot $\left(>36.5^{\circ} \mathrm{C}\right)$ regions without an apparent peak (Fig. $7 A, B$ ). Injection of RuR or menthol, or ablation of the antennal flagella did not increase the fraction of honey bees in cool $\left(<32.5^{\circ} \mathrm{C}\right)$ regions, demonstrating that these treatments do not affect honey bees' perception of low temperatures (Fig.
$7 A, B)$. It should be noted that injection of menthol or RuR or ablation of the antennal flagella did not impair the motor ability of the honey bees (data not shown). These results demonstrate that the antennal flagellum and RuR- or menthol-sensitive ion channels, including AmHsTRPA, are essential for warmth avoidance of honey bees.

Suppression of honey bee PER to sucrose by noxious heat and insect antifeedants are relieved in the presence of AmHsTRPA inhibitors

All of the AmHsTRPA activators identified above are derived from plants and known to be repellent to various plant predators, including insects (Nerio et al., 2010). Thus, camphor, AITC, and $\mathrm{CA}$ are expected to function as aversive-tasting substances for honey bees. To address this possibility, we used a PER assay. When the honey bee antennae were touched with $10 \%$ sucrose, honey bees extended their proboscises in $65.9 \pm 1.5 \%$ of the trials (Fig. 7C, Control). However, adding $3 \mathrm{~mm}$ camphor, $1 \mathrm{~mm}$ AITC, or $1 \mathrm{~mm}$ CA to the sucrose solution significantly reduced the response frequencies to $21.5 \pm 3.6 \%, 34.1 \pm 5.2 \%$, and $38.0 \pm$ $3.5 \%$, respectively, confirming their aversive effects on this behavior (Fig. 7C). Similar aversive responses were observed with the bitter substances $1 \mathrm{~mm}$ berberine and $1 \mathrm{~mm}$ quinine, which reduced the response probabilities to $26.3 \pm 3.4 \%$ and $29.8 \pm$ $1.4 \%$, respectively (Fig. 7C). Nevertheless, these compounds did not activate AmHsTRPA by a patch-clamp method (supplemental Fig. 5, available at www.jneurosci.org as supplemental material). Intriguingly, the response probability was also reduced to $33.3 \pm 3.2 \%$ by a hot $\left(45-50^{\circ} \mathrm{C}\right)$ sucrose solution (Fig. $7 C$, + Heat). Adding $10 \mu \mathrm{M}$ RuR to the sucrose solution did not affect the PER behavior $(67.1 \pm 2.7 \%)$; however, it relieved the suppression of PER by heat $(57.2 \pm 4.6 \%)$, camphor $(56.8 \pm 6.4 \%)$, AITC $(67.2 \pm 4.7 \%)$, and CA $(67.0 \pm 4.9 \%)$ to the control level. This effect was specific because suppression of PER by berberine 
A

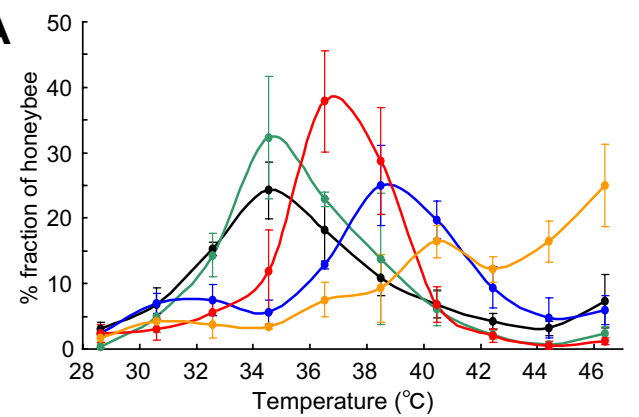

B

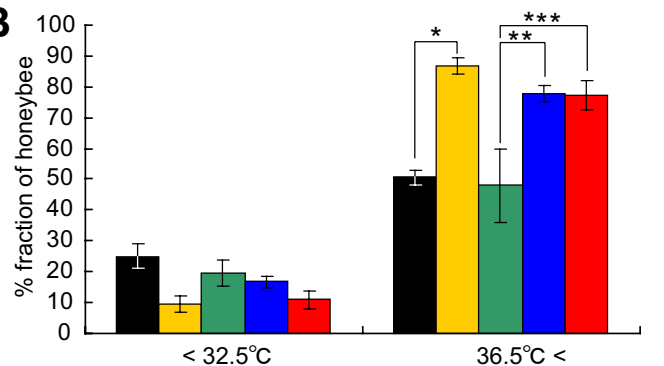

C

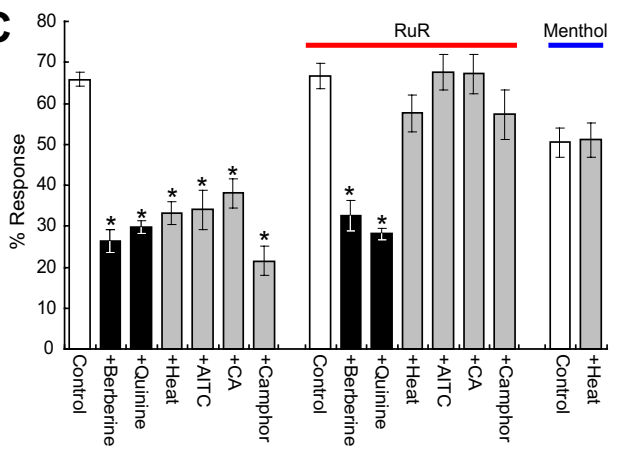

D
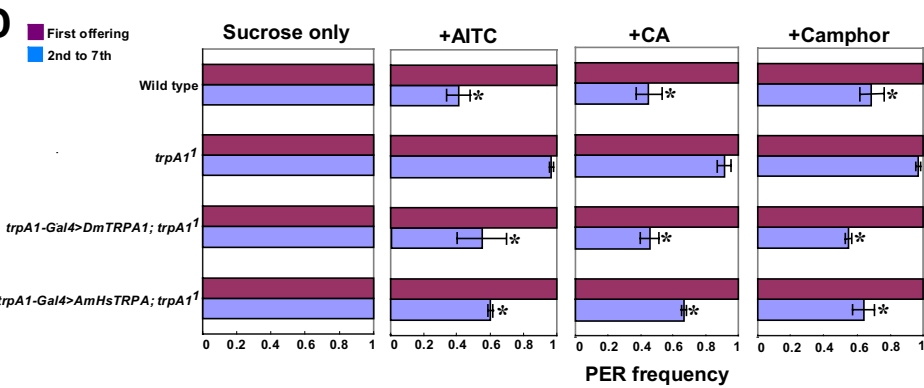

- Untreated

$\square$ Ablation of flagella

$\square$ Ringer

Menthol

$\square$ RuR

$\rightarrow$ Untreated $(n=30)$

$\rightarrow-$ Ringer $(n=29)$

Menthol $(n=30)$

$\rightarrow$ RuR ( $n=27$ )

- Ablation of flagella $(n=21)$

RuR

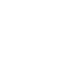


sitivity with $\mathrm{Ca}^{2+}$ imaging experiments (unpublished observation) and found that AmHsTRPA displayed a robust $\left[\mathrm{Ca}^{2+}\right]_{\mathrm{i}}$ increase upon temperature fluctuation. It is unlikely that honey bees contain only one thermosensitive TRP channel. They likely have other thermosensitive TRP channels with different temperature thresholds for activation from that of AmHsTRPA. There are several possible explanations for the lack of a robust $\left[\mathrm{Ca}^{2+}\right]_{\mathrm{i}}$ increase upon heat/cool stimulation in HEK293 cells expressing honey bee TRPA channels other than AmHsTRPA. For example, they may not be efficiently transported to the plasma membrane as a functional protein or have very low permeability to $\mathrm{Ca}^{2+}$. Some channels might be inactivated during mammalian cell culture at $33^{\circ} \mathrm{C}$. Alternatively, these channels may require association with other TRP channels or specific proteins for activation.

AmHsTRPA expressed in HEK293 cells apparently responds to heat but not cold. Rapid and robust current activation was observed at $33.9 \pm 0.6^{\circ} \mathrm{C}$ when heat was applied from $30^{\circ} \mathrm{C}$ (Fig. $2 E-H)$. This temperature threshold matches with honey bees' thermo behaviors in the hives (see below). The initial activation at $24.1 \pm 0.8^{\circ} \mathrm{C}$ when the temperature was raised from $15^{\circ} \mathrm{C}$ (Fig. $2 A-D$ ) could be an artifact of the in vitro experiments. If this also occurs in vivo, AmHsTRPA would be partially activated when the honey bees are inside the hive, where the temperature is maintained at $>30^{\circ} \mathrm{C}$ (Kronenberg and Heller, 1982; Fahrenholz et al., 1989; Seeley, 1995). Nevertheless, we observed negligible activation of AmHsTRPA while maintaining the temperature at $\sim 30^{\circ} \mathrm{C}$ (Fig. 2E,F). Whether AmHsTRPA is continuously activated in honey bee neurons at normal nest temperatures remains to be determined.

We have found that AmHsTRPA is also activated by AITC and $\mathrm{CA}$, as is mammalian TRPA1 (Fig. $3 A, B, D, E$ ). These noxious compounds activate mammalian TRPA1 by covalently modifying N-terminal cysteine residues (Hinman et al., 2006; Macpherson et al., 2007). These cysteine residues targeted for covalent modification were conserved in mammalian and Drosophila TRPA1 but not in AmHsTRPA (supplemental Fig. 7, available at www.jneurosci.org as supplemental material). This suggests that these electrophiles use different residues to activate AmHsTRPA, and they are probably not suitable for some electrophiles such as acrolein (supplemental Fig. 2, available at www.jneurosci.org as supplemental material). AmHsTRPA has seven cysteine residues between the first ankyrin repeat domain and the first transmembrane domain, which might be the targets of AITC and CA. Camphor, an inhibitor of mammalian TRPA1, quickly and robustly activates AmHsTRPA (Fig. 3C,F), similar to mammalian TRPV1 and TRPV3 (Moqrich et al., 2005; Xu et al., 2005). Camphor, AITC, and CA have long been known as insect antifeedants (Nerio et al., 2010), and this is also the case for honey bees (Fig. 7C). RuR-sensitive ion channels, including AmHsTRPA, are essential for suppressing the gustatory response to sucrose containing these aversive compounds in vivo (Fig. $7 C$ ). Furthermore, AmHsTRPA is able to complement the functions of DmTRPA1 as a chemical sensor in fruit flies (Fig. 7D) (Kang et al., 2010). Thus, it is likely that AmHsTRPA and DmTRPA1 are insect TRP channels responding to camphor, AITC, and CA, both in vivo and in vitro.

RuR inhibits AmHsTRPA activation by both heat and chemical stimuli (Fig. 4A,D-F). Meanwhile, menthol suppresses activation of AmHsTRPA in response to heat but not chemical stimuli (Fig. $4 B, C, G-I$ ). These results demonstrate that the activation mechanisms of AmHsTRPA by heat and chemical stimuli are different. Intriguingly, we have found that AmHsTRPA shows differential ion selectivity when activated by heat or chemical stimuli. It is more permeable to divalent cations $\left(\mathrm{Mg}^{2+}\right.$ and $\mathrm{Ca}^{2+}$ ) in response to camphor (and probably to AITC and CA) than in response to heat stimulation (Fig. 5G). Moreover, dual stimulation with heat and low concentration of camphor induced inward-rectified $I-V$ relationship with slightly negative reversal potentials, which were different from either heat or camphor stimulation alone (Fig. $5 H$ ). These results suggest that the gating mode is not uniform, but rather flexible depending on the types of stimuli. We speculate that aversive compounds, heat, and their combination induce different conformational changes in the AmHsTRPA channel and may also result in subtle structural changes in the pore region. The ion selectivity of the channels has conventionally been considered invariant; however, recent studies have determined that several channels, including TRP channels (Tominaga et al., 1998; Chung et al., 2008; Chen et al., 2009) and the P2X channel (Fujiwara and Kubo, 2004), can be modulated by activation time, type of stimulus, ligand concentration, channel density, and extracellular and intracellular ionic environments.

Similar to Drosophila TRP channels, AmHsTRPA is expressed in several appendages and the brain (Fig. 6) (Al-Anzi et al., 2006; Hamada et al., 2008). AmHsTRPA is likely to function as a ther$\mathrm{mal} / \mathrm{chemical}$ sensor in the appendages. Meanwhile, it may have different roles in the brain because the brain of the honey bee is much larger than that of Drosophila. Because antennae, legs, and proboscises contain AmHsTRPA-expressing neurons, these appendages would be able to sense the noxious compounds and heat. As shown in Figure $7 A-C$, this is indeed the case for antennae. The results of the honey bee thermotaxis assay demonstrated that groups of honey bees prefer temperatures $\sim 35^{\circ} \mathrm{C}$, comparable to a previous report (Grodzicki and Caputa, 2005). Moreover, this thermal preference is quite consistent with the temperature threshold for AmHsTRPA activation determined in vitro (33.9 \pm $0.6^{\circ} \mathrm{C}$ ) (Fig. $2 \mathrm{H}$ ). Injection of menthol or RuR to suppress the activity of AmHsTRPA significantly increases the fraction of bees in warmer regions (Fig. $7 A, B$ ), demonstrating that menthol- or RuR-sensitive ion channels, including AmHsTRPA, are essential for avoidance of temperatures $>36.5^{\circ} \mathrm{C}$. Although we could not rule out the contribution of other RuR- or menthol-sensitive channels to thermal and chemical avoidance, the compensatory effect of AmHsTRPA expressed in dtrpA1-deficient flies in PER assay suggests that AmHsTRPA may play key roles in avoidance behaviors in honey bees (Fig. 7D). The AmHsTRPA inhibitors were used for the experiments because it was not possible to knock down the functions of AmHsTRPA by RNA interference in adult bees. As shown in Figure $7 A$ and $B$, honey bees with the ablated antennal flagella accumulated in much warmer regions than those injected with either RuR or menthol. First of all, the inhibitors injected into the head may only partially suppress AmHsTRPA activation in the antennae. Under this condition, it is also possible to propose that the flagellum may have TRP or other channels with the higher temperature threshold for activation than AmHsTRPA, and they function to elicit avoidance behavior against high temperatures $>44^{\circ} \mathrm{C}$. As described previously, the temperature of the hive is under the control of worker bees; in particular, the brood nest temperatures are maintained at 32$36^{\circ} \mathrm{C}$ to support optimal development of larvae and pupae (Kronenberg and Heller, 1982; Fahrenholz et al., 1989; Seeley, 1995; Tautz et al., 2003). Thus, we propose that AmHsTRPA functions to detect an increase in the brood nest temperature $>36^{\circ} \mathrm{C}$ and induce nest-cooling behavior. Fruit flies have evolved DmTRPA1 with a temperature threshold at $25-29^{\circ} \mathrm{C}$ 
to detect their optimal temperature (Hamada et al., 2008). Furthermore, NvHsTRPA does not appear to have a specific temperature threshold for activation (Matsuura et al., 2009). Thus, development of AmHsTRPA could be considered one of the important steps in establishing sociality in honey bees.

As we reported previously, HsTRPA has been arisen by the duplication of Wtrw gene, which is necessary for detecting moist air in Drosophila, and intriguingly Hymenoptera lacks TRPA1, which was present in the last common ancestor of Bilateria (Matsuura et al., 2009; Kang et al., 2010). As shown in Figure 7D, AmHsTRPA and DmTRPA1 are functionally equivalent as a chemical sensor, suggesting that AmHsTRPA has gained the chemical and thermal responsive properties during evolution, which has resulted in the loss of ancient TRPA1 in honey bees. As far as we know, this is the first example of "neofunctionalization" of duplicated ion channel gene followed by loss of the functionally equivalent ancient gene.

\section{References}

Adams DJ, Dwyer TM, Hille B (1980) The permeability of endplate channels to monovalent and divalent metal cations. J Gen Physiol 75:493-510.

Al-Anzi B, Tracey WD Jr, Benzer S (2006) Response of Drosophila to wasabi is mediated by painless, the fly homolog of mammalian TRPA1/ ANKTM1. Curr Biol 16:1034-1040.

Bischof J, Maeda RK, Hediger M, Karch F, Basler K (2007) An optimized transgenesis system for Drosophila using germ-line-specific phiC31 integrases. Proc Natl Acad Sci U S A 104:3312-3317.

Caterina MJ, Schumacher MA, Tominaga M, Rosen TA, Levine JD, Julius D (1997) The capsaicin receptor: a heat-activated ion channel in the pain pathway. Nature 389:816-824.

Chen J, Kim D, Bianchi BR, Cavanaugh EJ, Faltynek CR, Kym PR, Reilly RM (2009) Pore dilation occurs in TRPA1 but not in TRPM8 channels. Mol Pain 5:3.

Chung MK, Güler AD, Caterina MJ (2008) TRPV1 shows dynamic ionic selectivity during agonist stimulation. Nat Neurosci 11:555-564.

Clapham DE (2007) SnapShot: Mammalina TRP channels. Cell 129:220.

de Brito Sanchez MG, Giurfa M, de Paula Mota TR, Gauthier M (2005) Electrophysiological and behavioural characterization of gustatory responses to antennal "bitter" taste in honeybees. Eur J Neurosci 22: 3161-3170.

Eid SR, Crown ED, Moore EL, Liang HA, Choong KC, Dima S, Henze DA, Kane SA, Urban MO (2008) HC-030031, a TRPA1 selective antagonist, attenuates inflammatory- and neuropathy-induced mechanical hypersensitivity. Mol Pain 4:48.

Fahrenholz L, Lamprecht I, Schricker B (1989) Thermal investigation of a honey bee colony: thermoregulation of the hive during summer and winter and heat production of members of different bee castes. J Comp Physiol B 159:551-560.

Fujiwara Y, Kubo Y (2004) Density-dependent changes of the pore properties of the P2X2 receptor channel. J Physiol 558:31-43.

Grodzicki P, Caputa M (2005) Social versus individual behaviour: a comparative approach to thermal behaviour of the honeybee (Apis mellifera $L$ ) and the American cockroach (Periplaneta americana L). J Insect Physiol 51:315-322.

Hamada FN, Rosenzweig M, Kang K, Pulver SR, Ghezzi A, Jegla TJ, Garrity PA (2008) An internal thermal sensor controlling temperature preference in Drosophila. Nature 454:217-220.

Heinrich B (1996) How the honey bee regulates its body temperature. Bee World 77:130-137.

Hille B (2001) Ionic channels of excitable membranes. Sunderland, MA: Sinauer.

Hinman A, Chuang HH, Bautista DM, Julius D (2006) TRP channel activation by reversible covalent modification. Proc Natl Acad Sci U S A 103:19564-19568.

Kang K, Pulver SR, Panzano VC, Chang EC, Griffith LC, Theobald DL, Garrity
PA (2010) Analysis of Drosophila TRPA1 reveals an ancient origin for human chemical nociception. Nature 464:597-600.

Kim SH, Lee Y, Akitake B, Woodward OM, Guggino WB, Montell C (2010) Drosophila TRPA1 channel mediates chemical avoidance in gustatory receptor neurons. Proc Natl Acad Sci U S A 107:8440-8445.

Kronenberg F, Heller C (1982) Colonial thermoregulation in honey bees (Apis mellifera). J Comp Physiol B 148:65-76.

Kwon Y, Shim HS, Wang X, Montell C (2008) Control of thermotactic behavior via coupling of a TRP channel to a phospholipase C signaling cascade. Nat Neurosci 11:871-873.

Lee Y, Lee Y, Lee J, Bang S, Hyun S, Kang J, Hong ST, Bae E, Kaang BK, Kim J (2005) Pyrexia is a new thermal transient receptor potential channel endowing tolerance to high temperatures in Drosophila melanogaster. Nat Genet 37:305-310.

Liu L, Li Y, Wang R, Yin C, Dong Q, Hing H, Kim C, Welsh MJ (2007) Drosophila hygrosensation requires the TRP channels water witch and nanchung. Nature 450:294-298.

Macpherson LJ, Dubin AE, Evans MJ, Marr F, Schultz PG, Cravatt BF, Patapoutian A (2007) Noxious compounds activate TRPA1 ion channels through covalent modification of cysteines. Nature 445:541-545.

Matsuura H, Sokabe T, Kohno K, Tominaga M, Kadowaki T (2009) Evolutionary conservation and changes in insect TRP channels. BMC Evol Biol 9:228

Moqrich A, Hwang SW, Earley TJ, Petrus MJ, Murray AN, Spencer KS, Andahazy M, Story GM, Patapoutian A (2005) Impaired thermosensation in mice lacking TRPV3, a heat and camphor sensor in the skin. Science 307:1468-1472.

Nerio LS, Olivero-Verbel J, Stashenko E (2010) Repellent activity of essential oils: a review. Bioresour Technol 101:372-378.

Nishino H, Nishikawa M, Mizunami M, Yokohari F (2009) Functional and topographic segregation of glomeruli revealed by local staining of antennal sensory neurons in the honeybee Apis mellifera. J Comp Neurol 515:161-180.

Rosenzweig M, Brennan KM, Tayler TD, Phelps PO, Patapoutian A, Garrity PA (2005) The Drosophila ortholog of vertebrate TRPA1 regulates thermotaxis. Genes Dev 19:419-424.

Sayeed O, Benzer S (1996) Behavioral genetics of thermosensation and hygrosensation in Drosophila. Proc Natl Acad Sci U S A 93:6079-6084.

Seeley TD (1995) The wisdom of the hive. Cambridge, MA: Harvard UP.

Sokabe T, Tsujiuchi S, Kadowaki T, Tominaga M (2008) Drosophila painless is a $\mathrm{Ca}^{2+}$-requiring channel activated by noxious heat. J Neurosci 28:9929-9938.

Tautz J, Maier S, Groh C, Rössler W, Brockmann A (2003) Behavioral performance in adult honey bees is influenced by the temperature experienced during their pupal development. Proc Natl Acad Sci U S A 100:7343-7347.

Tominaga M, Caterina MJ, Malmberg AB, Rosen TA, Gilbert H, Skinner K, Raumann BE, Basbaum AI, Julius D (1998) The cloned capsaicin receptor integrates multiple pain-producing stimuli. Neuron 21:531-543.

Tracey WD Jr, Wilson RI, Laurent G, Benzer S (2003) painless, a Drosophila gene essential for nociception. Cell 113:261-273.

Tsuchimoto M, Yasuo S, Funada M, Aoki M, Sasagawa H, Yoshimura T, Tadauchi O, Cameron SA, Kitagawa Y, Kadowaki T (2005) Conservation of novel Mahya genes shows the existence of neural functions common between Hymenoptera and Deuterostome. Dev Genes Evol 215: $564-574$.

Xiao B, Dubin AE, Bursulaya B, Viswanath V, Jegla TJ, Patapoutian A (2008) Identification of transmembrane domain 5 as a critical molecular determinant of menthol sensitivity in mammalian TRPA1 channels. J Neurosci 28:9640-9651.

Xu H, Blair NT, Clapham DE (2005) Camphor activates and strongly desensitizes the transient receptor potential vanilloid subtype 1 channel in a vanilloid-independent mechanism. J Neurosci 25:8924-8937.

Yokohari F (1983) The coleocapitular sensillum, an antennal hygro- and thermoreceptive sensillum of the honey bee, Apis mellifera L. Cell Tissue Res 233:355-365.

Yokohari F, Tominaga Y, Tateda H (1982) Antennal hygroreceptors of the honey bee, Apis mellifera L. Cell Tissue Res 226:63-73. 